\title{
Peptídeo relacionado ao gene da calcitonina por iontoforese na viabilidade de retalho cutâneo randômico em ratos $^{1}$
}

\author{
Calcitonin gene-related peptide by iontophoresis on the viability of the randon skin flaps \\ in rats
}

\author{
Ivaldo Esteves Junior², Lydia Masako Ferreira ${ }^{3}$, Richard Eloin Liebano² \\ 1. Trabalho da Disciplina de Cirurgia Plástica da Universidade Federal de São Paulo - Escola Paulista de Medicina (UNIFESP-EPM). \\ 2. Mestre em Ciências Básicas pelo Programa de Pós-Graduação em Cirurgia Plástica Reparadora UNIFESP-EPM. \\ 3. Professora Titular da Disciplina de Cirurgia Plástica da UNIFESP-EPM.
}

\begin{abstract}
RESUMO
Objetivo: Investigar o efeito da administração tópica do peptídeo relacionado ao gene da calcitonina (CGRP) por iontoforese na viabilidade de retalho cutâneo randômico em ratos. Métodos: Sessenta ratos Wistar EPM-1, adultos e machos foram submetidos a retalho cutâneo randômico. Os animais foram distribuídos aleatoriamente em quatro grupos. Nos animais do grupo 1 (controle, $\mathrm{n}=15$ ) realizou-se simulação de estímulo elétrico, no grupo 2 (iontoforese placebo, $\mathrm{n}=15$ ) os animais foram submetidos à corrente contínua, no grupo 3 (controle de absorção, $n=15$ ) os animais receberam simulação de estímulo elétrico com CGRP e, por fimm os animais do grupo 4 (tratado, $\mathrm{n}=15$ ) foram tratados com iontoforese de CGRP. Em todos os grupos estes procedimentos foram realizados imediatamente após a técnica operatória e nos dois dias subsequentes. A porcentagem da área de necrose foi avaliada no sétimo dia de pós-operatório. Resultados: A média das porcentagens das áreas de necrose foram: grupo 1- 48\%, grupo 2 $51 \%$, grupo $3-46 \%$ e, grupo $4-28 \%$. A análise estatística, através do teste de Kruskal-Wallis, evidenciou diferença significante $(\mathrm{p}<0,001)$. Conclusão: a administração tópica de CGRP por iontoforese é eficaz em aumentar a viabilidade de retalho cutâneo randômico em ratos.
\end{abstract}

Descritores: Receptores Cgrp. Retalhos cirúrgicos. Iontoforese. Ratos.

\begin{abstract}
Purpose: Assess the effect of the local administration of calcitonin gene-related peptide (CGRP) by iontophoresis on the viability of random skin flap in rats. Methods: Sixty Wistar-EPM 1 rats were submitted to dorsal skin flap of cranial base $10 \mathrm{x} 4 \mathrm{~cm}$ with interposition of a plastic barrier between the skin flap and the donnor site. The animals were randomly distributed in four groups $(\mathrm{n}=15$ in each group) and were treated as follows: in group 1 (control), animals were submitted to a simulation of electrical current for 20 minutes; group 2, (iontophoresis placebo) animals were submitted to direct current of $4 \mathrm{~mA}$ amplitude for 20 minutes; group 3 (absorption control) receive simulation of electrical current for 20 minutes with CGRP on one of the electrodes; group 4 (iontophoretically treated) treated by iontophoresis with CGRP. In all groups the procedures were performed immediately after the surgery and the two subsequent days. Results: The percentage of the necrosis area was calculated in all groups on the seventh postoperative day and results were as follows: group 1- 48\%; group $2-51 \%$; group $3-46 \%$ and group $4-28 \%$. The statistical analysis presented significant difference when the comparison of group 4 to the other groups. Conclusion: The topical administration of the CGRP by iontophoresis is efficient to increase the viability of the random skin flap random in rats.
\end{abstract}

Key words: Receptors, Calcitonin Gene-Related Peptide. Surgical Flaps. Iontophoresis. Rats.

\section{Introdução}

A Cirurgia Plástica é uma especialidade que, com freqüência, utiliza-se em seu arsenal terapêutico dos retalhos cutâneos, principalmente nas cirurgias reconstrutoras. Porém, falhas na transferência do retalho podem ocorrer, culminando, não raro, com o insucesso do tratamento proposto. Os eventos que levam à diminuição na área de viabilidade do retalho podem 
ser atribuídos a uma série de fatores extrínsecos e intrínsecos. Os fatores extrínsecos incluem condições sistêmicas (infecção, inflamação, arteriosclerose, hipotensão e má-nutrição) e causas locais (compressão, tensão, trombos ou torção no pedículo) que, contrastam diretamente com o único fator intrínseco associado, a insuficiência arterial do retalho. Esta complicação seria explicada pela secção de vasos cutâneos e de terminais nervosos simpáticos, à elevação do retalho, que provocariam a diminuição do fluxo sangüíneo ao longo do mesmo ${ }^{1}$.

Trabalhos que investigaram técnicas relacionadas ao aumento do aporte sanguíneo com o intuito de melhorar a condição isquêmica do retalho e, logo, aumentar a área de viabilidade deste, foram publicados ${ }^{2-8}$. Alguns destes utilizaramse de correntes elétricas e, seus resultados baseiam-se em duas teorias hipotéticas: a primeira seria a inibição de fibras simpáticas vasoconstritoras e, a segunda e mais aceita, seria a liberação de alguns neuropeptídeos como a substância P e o CGRP, que são encontrados nas terminações das fibras nervosas do tipo $\mathrm{C}$ e seriam liberadas através de estimulação elétrica antidrômica ${ }^{6,8}$.

Outros autores têm investigado o papel do CGRP (837 ), antagonista do CGRP, que gera a diminuição dos efeitos do ultimo e, com isto, diminuição da capacidade local na melhora da vascularização perante os tratamentos propostos ${ }^{5,6,9}$.

O CGRP é uma substância endógena descrita como um potente vasodilatador ${ }^{10,11}$, encontra-se na maior parte das lesões tissulares atuando, com efeito, regulador na isquemia ${ }^{11}$ e, sua eficácia em aumentar a área de viabilidade de retalhos cutâneos pode ser observada quando administrada sistemicamente ${ }^{2,3,5,7}$.

A iontoforese é um recurso que foi descrito pela primeira vez há quase um século e usada como intervenção clínica há mais de 40 anos. Como muitas intervenções terapêuticas, existem poucos estudos de pesquisas experimentais que mostrem seus efeitos, restringindo-se a relatos de casos e comentários clínicos. Iontoforese é a transmissão de íons através da pele intacta, com introdução de substâncias sob a pele com fins terapêuticos, através da utilização de uma elétrica contínua. Caracteriza-se, assim, como técnica de aplicação tópica, podendo gerar seus efeitos locais sem possíveis e talvez indesejáveis alterações sistêmicas. Atualmente o uso desta técnica vem ressurgindo ${ }^{4,12} \mathrm{e}$, oferece promessa de eficácia terapêutica e de custos.

Logo, o objetivo deste estudo foi investigar o efeito da administração tópica do CGRP por iontoforese na viabilidade do retalho cutâneo randômico em ratos.

\section{Métodos}

Sessenta ratos Wistar-EPM1, adultos e machos pesando entre 320 e 356 g foram utilizados neste experimento. Estes foram mantidos em gaiolas individuais com temperatura ambiente entre $23^{\circ}$ e $25^{\circ} \mathrm{C}$ e, com ciclos de 12 horas em claro/ escuro recebendo ração comercial e água ad libitum.

Os animais foram anestesiados com injeção intraperitoneal de Cloridrato de Tiletamina $(25 \mathrm{mg} / \mathrm{kg})$ e Cloridrato de Zolazepan $(25 \mathrm{mg} / \mathrm{kg})$ previamente ao ato operatório e durante as sessões de tratamento. Após a indução anestésica os animais foram posicionados em superfície plana com extensão dos membros e realizou-se subseqüente tricotomia digital no dorso dos mesmos. Em seguida, o retalho cutâneo randômico de base cranial, com dimensões de $10 \mathrm{~cm}$ de comprimento e $4 \mathrm{~cm}$ de largura, foi demarcado, respeitando-se como limites os ângulos inferiores das escápulas e os ossos superiores da cintura pélvica. Os retalhos foram elevados do dorso dos animais, seguindo modelo experimental ${ }^{13,14}$ e, continham a fáscia superficial, panículo carnoso, tecido subcutâneo e pele, estes foram colocados na mesma posição com interposição de uma barreira plástica com as mesmas dimensões $(10 \times 4 \mathrm{~cm})$. A sutura foi realizada através de pontos simples com fio de náilon monofilamentar 4-0 de 1 em $1 \mathrm{~cm}$.

Estes animais foram distribuídos aleatoriamente em quatro grupos de 15 animais cada. Os animais do grupo 1 foram utilizados como controle recebendo colocação dos eletrodos (3,0x 5,0 cm), do eletroestimulador (EGF, Carci®, São Paulo, Brasil), na base do retalho e no abdome sendo, que o eletrodo da base foi conectado ao ânodo (positivo) e o do abdome ao cátodo (negativo), entre os eletrodos e a pele dos animais foram interpostas almofadas de gaze umedecidas com $4 \mathrm{ml}$ de solução fisiológica (SF) e, estas permaneceram nesta posição durante 20 minutos, porém sem a emissão de qualquer estímulo pelo eletroestimulador. Nos animais do grupo 2 os mesmos procedimentos do grupo 1 foram realizados e, nestes o eletroestimulador emitiu corrente contínua com amplitude de $4 \mathrm{~mA}$. Os animais do grupo 3 foram, também, submetidos aos mesmos procedimentos realizados no grupo 1, substituindo-se a SF, encontrada na almofada de gaze sob o eletrodo positivo, por $4 \mathrm{ml}$ de CGRP (Tocris Koockson Inc., Missouri, USA) diluído em $\mathrm{SF}$ à concentração de $10{ }^{6} \mathrm{M}$. Nos animais do grupo 4 o mesmo tratamento realizou-se em relação aos animais do grupo 3 sendo que o eletroestimulador emitiu a corrente contínua com amplitude de $4 \mathrm{~mA}$ por $20 \mathrm{~min}$. Estes procedimentos realizaram-se imediatamente após a técnica operatória e nos dois dias subsequentes.

A porcentagem da área de necrose dos retalhos foi verificada no sétimo dia de pó-operatório por meio do método de gabarito de papel ${ }^{15}$, salientando-se que todos os procedimentos de tratamento e de avaliação foram realizados em estudo duplo cego.

Para se avaliar as possíveis diferenças quanto à porcentagem da área de necrose entre esses mesmos grupos utilizou-se o teste não paramétrico para " $k$ " amostras independentes de Kruskal-Wallis, complementado pelo teste de comparações múltiplas. O nível de rejeição para a hipótese de nulidade foi fixado sempre em um valor menor ou igual a 0,05 $(5 \%)$.

\section{Resultados}

A média das porcentagens da área de necrose dos retalhos nos ratos foi de: grupo 1 - $48 \%$; grupo 2 - $51 \%$; grupo $3-46 \%$ e grupo $4-28 \%$.

O teste de Kruskal-Wallis evidenciou diferença estatisticamente significante entre os grupos $(p<0,001)$ com G4< 
G3,G2,G1(Figura 1).

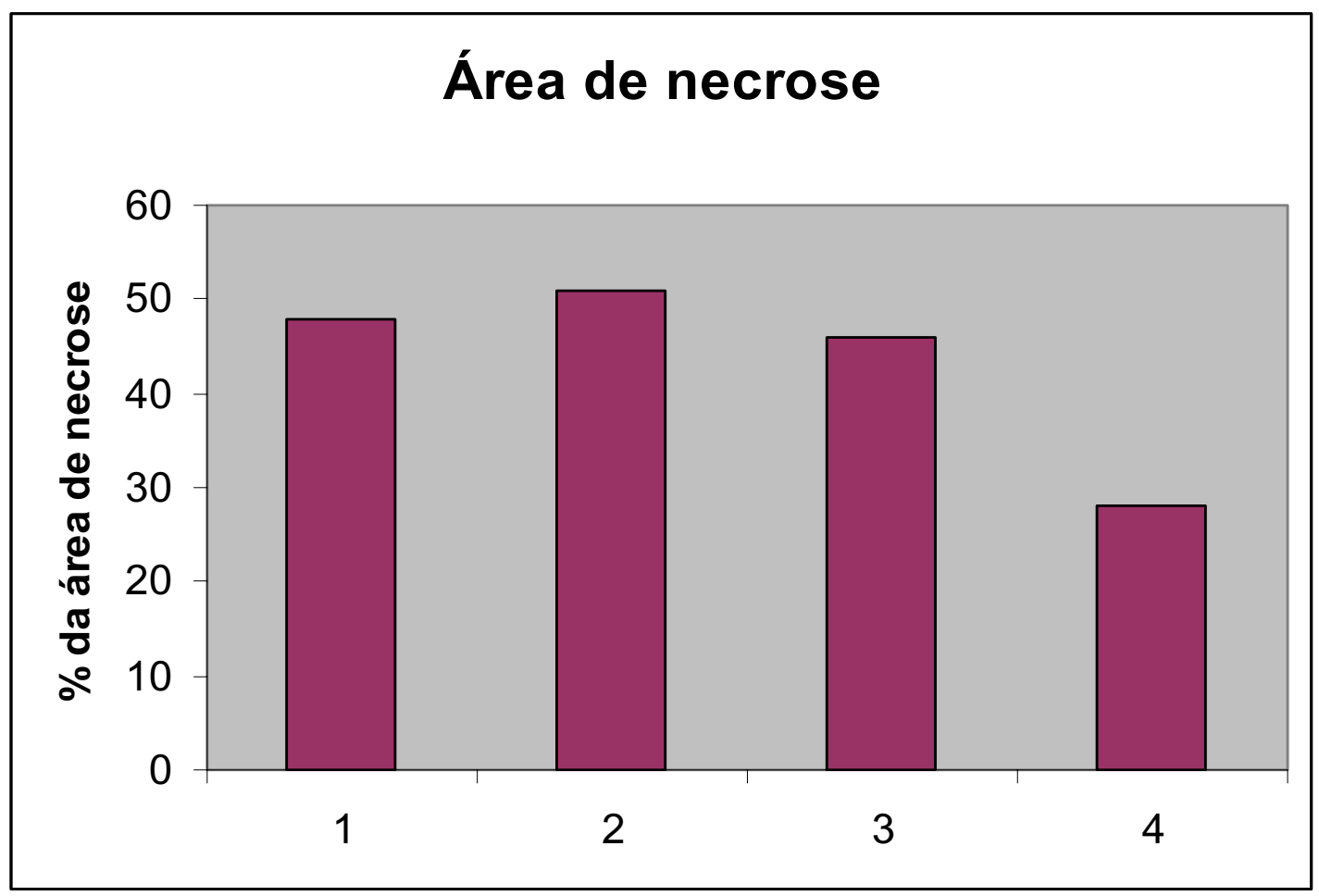

FIGURA 1 - Área de necrose do retalho cutâneo: grupo controle (1), grupo iontoforese placebo (2), grupo controle de absorção (3) e, grupo tratado (4), n=15 em cada grupo.

\section{Discussão}

Os eventos fisiopatológicos que ocorrem na porção distal do retalho cutâneo ainda não são precisamente entendidos, porém a diminuição do fluxo sanguíneo e, logo, a insuficiência arterial do retalho aparece como a principal causa de necrose e perda deste. Kerrigan ${ }^{2}$ sugere que modalidades terapêuticas que aumentem o fluxo sanguíneo para o retalho cutâneo ou estabilizem a membrana celular do tecido isquêmico devem ser abordadas.

Embora é sabido que a pele do porco é a que mais se assemelha à humana o modelo de retalho cutâneo em ratos foi adotado devido a facilidade na obtenção e no manuseio além de baixo custo deste animal.

Neste estudo, foi utilizado o modelo de retalho cutâneo dorsal de base cranial, com dimensões de 10x4 cm, desenvolvido por McFarlane e col. ${ }^{13}$ como modelo experimental para se estudar a necrose e prevenção da mesma. Uma barreira plástica impermeável, de mesmas dimensões do retalho, foi interposta entre este e o leito doador a fim de se impedir a revascularização através de vasos do leito, garantindo assim condições homogêneas de isquemia e necrose ${ }^{16,17}$.

O método de gabarito de papel descrito por Sasaki, Pang ${ }^{15}$ foi utilizado para se avaliar a área de necrose, principalmente, por expressar confiabilidade, com erro $<5 \%$, além de possuir rápida e fácil aplicabilidade ${ }^{8}$.

Os resultados encontrados neste trabalho mostraram similaridade com aqueles que utilizaram administração sistêmica de $\mathrm{CGRP}^{2,3,5,7}$, bem como com aqueles que se utilizaram estimulação elétrica pura ${ }^{6,8}$, sendo que os últimos relacionam seus resultados satisfatórios, em relação ao aumento na área de viabilidade do retalho cutâneo, à liberação local de CGRP, contudo a proposta terapêutica aqui abordada administra tal substância de forma tópica, independente de possíveis fatores que venham a impedir a administração sistêmica deste vasodilatador.

O procedimento iontoforético apresentou como parâmetros amplitude de $4 \mathrm{~mA}$ durante 20 minutos de tratamento em observação ao trabalho de Asai e col. ${ }^{4}$ na administração da prostaglandina E1. Esta dose foi eficaz em ambos os procedimentos, porém não vem a confirmar que esta é a melhor dose para a administração destas substâncias ou de qualquer outra sendo, que novos estudos de parâmetros para o procedimento iontoforético podem vir a auxiliar em pesquisas na área.

O eletrodo posicionado na base do retalho foi utilizado como eletrodo de administração, ou ativo, e, este foi conectado ao ânodo do eletroestimulador, pois o CGRP é um cátion ${ }^{12}$. Desta forma a força motriz da iontoforese pode ser gerada por repulsão de cargas iguais.

O CGRP foi utilizado à concentração de $10-{ }^{6} \mathrm{M}$, pois, na literatura por nós pesquisada ${ }^{7}$, esta demonstrou melhores 
resultados em se aumentar a área de viabilidade de retalhos cutâneos experimentais. Contudo, vale ressaltar que esta foi a concentração mais alta do estudo de Jansen e col.7 sugerindo que concentrações mais altas que estas podem ser mais eficientes.

Novos estudos podem surgir vindo a corroborar com estas questões e, logo, contribuindo a esta área da cirurgia que vem acolhendo os recursos físicos como coadjuvante.

\section{Conclusão}

A administração tópica de CGRP por iontoforese é eficaz em aumentar a viabilidade do retalho cutâneo randômico em ratos.

\section{Referências}

1. Kerrigan CL. Skin flap failure: pathophysiology. Plast Reconstr Surg. 1983; 72(6): 766-77.

2. Kjartansson J, Dalsgaard CJ. Calcitonin gene-related peptide increases survival of a musculocutaneous critical flap in the rat. Eur J Pharmacol. 1987; 142(3): 355-8.

3. Kjartansson J, Lundeberg T, Samuelson UE, Dalsgaard CJ, Heden P. Calcitonin gene-related peptide (CGRP) and transcutaneous electrical nerve stimulation (TENS) increase cutaneous blood flow in a musculocutaneous flap in the rat. Acta Physiol Scand. 1988; 134(1): 89-94.

4. Asai S, Fukuta K, Torii S. Topical administration of prostaglandin E1 with iontophoresis for skin flap viability. Ann Plast Surg. 1997; 38(5): 514-7.

5. Gherardini G, Gurleck A, Milner SM, Matarasso A, Evans GR, Jernbeck J, Lundebergh T. Calcitonin gene-related peptide improves skin flap survival and tissue inflammation. Neuropeptides 1998; 32(3): 269-73.

6. Gherardini G, Lundeberg T, Cui JG, Eriksson SV, Trubek S, Linderoth B. Spinal cord stimulation improves survival in ischemic skin flaps: an experimental study of the possible mediation by calcitonin generelated peptide. Plast Reconstr Surg. 1999; 103(4): 1221-8.
7. Jansen GB, Torkvist L, Lofgren O, Raud J, Lundeberg T. Effects of calcitonin gene-related on tissue survival, blood flow and neutrophil recruitment in experimental skin flaps. Br J Plast Surg. 1999; 52(4): 299-303.

8. Liebano RE, Ferreira LM, Neto MS. The effect of trans-cutaneous electrical nerve stimulation on the viability of randon skin flaps in rats. Can J Plast Surg. 2002; 10(4): 151-4.

9. Chu DQ, Legon S, Smith DM, Costa SK, Cuttitta F, Brain SD. The calcitonin gene-related peptide (CGRP) antagonist CGRP (8-37) blocks vasodilatation in inflamed rat skin: involvement of adrenomedullin in addition to CGRP. Neurosci Lett. 2001; 310(23): 169-72.

10. Brain SD, Willians TJ, Tippins JR, Morris HR, MacIntyre I. Calcitonin gene-related peptide is potent vasodilator. Nature 1985; 313(5997): 54-6.

11. Gherardini G, Evans GR, Theodorsson E, Gurleck A, Milner SM, Palmer B, Lundeberg T. Calcitonin gene-related peptide in experimental ischemia. Implication of an endogenous anti-ischemic effect. Ann Plast Surg. 1996; 36(6): 616-20.

12. Gherardini G, Gurleck A, Evans GR, Milner SM, Matarasso A, Wassler M, Jernbeck J, Lundeberg T. Venous Ulcers: improved healing by iontophoretic administration of calcitonin gene-related and vasoactive intestinal polypeptide. Plast Reconstr Surg. 1998; 101(1): 90-3.

13. McFarlane RM, Deyoung G, Henry RA. The design of a pedicle flap in the rat to study necrosis and its prevention. Plast Reconstr Surg. 1965; 35: 177-82.

14. Liebano RE, Ferreira LM, Sabino Neto M. Modelo experimental para estimulação elétrica nervosa transcutanea em retalho cutâneo randômico isquêmico em ratos. Acta Cir Bras. 2003; 18: 54-9.

15. Sasaki GH, Pang CY. Hemodynamics and viability of acute neurovascular island skin flaps in rats. Plast Reconstr Surg. 1980; 65(2): $152-8$.

16. Korlof B, Ugland O. Flaps and flap necrosis. Improving the circulation in skin flaps with Complamin and with Dicoumarol: animal experiments Acta Chir Scand. 1966; 131(5): 408-12.

17. Kaufman T, Angel MF, Eichenlaub EH, Levin M, Hurwitz DJ, Futrell JW. The salutary effects of the bed on the survival of experimental flaps. Ann Plast Surg. 1985; 14(1): 64-73.
Correspondência:

Ivaldo Esteves Junior

Rua Napoleão de Barros, $715 / 4^{\circ}$ andar

04024-900 São Paulo - SP

Tel: (11)5576-4118

Fax: (11)5571-6579

sandra.dcir@epm.br

ivaldofisio@ig.com.br
Conflito de interesse: nenhum

Fonte de financiamento: Capes

\section{Como citar este artigo:}

Esteves Junior I, Ferreira LM, Liebano RE. Peptídeo relacionado ao gene da calcitonina por iontoforese na viabilidade de retalho cutâneo randômico em ratos. Acta Cir Bras [serial online] 2004 Nov-Dez;19(6). Disponível em URL: http://www.scielo.br/acb [também em CD-ROM].

\section{*Figura colorida disponível em www.scielo.br/acb}

Recebimento: 25/08/2004

Revisão: 20/09/2004

Aprovação: 18/10/2004 